\title{
The effects of sodium glucose co-transporter (SGLT) 2 inhibitors on hematocrit levels: a systematic review and meta-analysis of randomized controlled trials
}

\author{
Xiaonan Wang ${ }^{1,2}$, Ran Fu ${ }^{1,2}$, Hongtao Liu ${ }^{2}$, Yinling $\mathrm{Ma}^{2}$, Xuejia Qiu ${ }^{2}$, Zhanjun Dong ${ }^{1,2}$ \\ ${ }^{1}$ Graduate School of Hebei Medical University, Shijiazhuang, China; ${ }^{2}$ Department of Pharmacy, Hebei General Hospital, Shijiazhuang, China \\ Contributions: (I) Conception and design: Z Dong, X Wang; (II) Administrative support: Z Dong; (III) Provision of study materials or patients: X \\ Wang, R Fu; (IV) Collection and assembly of data: X Wang, R Fu; (V) Data analysis and interpretation: X Wang, H Liu, Y Ma; (VI) Manuscript \\ writing: All authors; (VII) Final approval of manuscript: All authors. \\ Correspondence to: Zhanjun Dong. Department of Pharmacy, Hebei General Hospital. No.348 West Heping Road, Shijiazhuang 050051, China. \\ Email: dzjhbgh@163.com.
}

Background Previous studies have suggested benefits of sodium glucose co-transporter 2 (SGLT2) inhibitors
including improving glycemic control, lower body weight, uric acid-lowering effect and decreasing blood
pressure. The aim of this study was to evaluate the effects of SGLT2 inhibitors on hematocrit (Hct) levels in
patients with type 2 diabetes mellitus.
Methods: Embase, CENTRAL, PubMed and other databases were searched from the establishment of the
database through to July 2020. Randomized controlled trials (RCTs) involving patients with type 2 diabetes
mellitus who were treated with SGLT2 inhibitors were analyzed using the random effects model. Stata 12.0
statistical software was used to estimate the weighted mean difference (WMD) and the 95\% confidence
intervals (CIs).

Results: A total of 40 RCTs were included, comprising 21,050 patients. SGLT2 inhibitors resulted in a significant increase in Hct levels compared to patients treated with a placebo (WMD 2.67\%, 95\% CI, 2.53 to $2.82 ; \mathrm{P}<0.001)$. Treatment with $2.5,5$, and $10 \mathrm{mg}$ of dapagliflozin significantly increased Hct levels (WMD $1.96 \%, 2.27 \%$, and $2.47 \%$, respectively; $\mathrm{P}<0.001)$. Administration of 100 and $300 \mathrm{mg}$ of canagliflozin also resulted in a significant increase in Hct (WMD 2.91\% and 2.94\%, respectively; $\mathrm{P}<0.001$ ). Similarly, empagliflozin, at concentrations of 10 and $25 \mathrm{mg}$, caused a significant increase in Hct (WMD 3.39\% and $3.44 \%$, respectively; $\mathrm{P}<0.001)$. However, treatment with ipragliflozin $(12.5$ and $50 \mathrm{mg}$ ) and ertugliflozin $(5$ and $15 \mathrm{mg}$ ) only resulted in a slight increase in patient Hct levels (WMD 1.26\% and 1.98\%, respectively for ipragliflozin, P>0.05; WMD 2.24\% and 2.64\%, respectively for ertugliflozin; P>0.05).

Discussion: SGLT2 inhibitors, as a class of drugs, increased Hct levels in patients with type 2 diabetes, and this increase was slightly more pronounced at higher doses compared to lower doses.

Trial registration: The protocol of this study has been submitted to the PROSPERO platform (https:// www.crd.york.ac.uk/PROSPERO/), and the registration number is CRD42020200699.

Keywords: Sodium glucose co-transporter 2 inhibitors (SGLT2 inhibitors); hematocrit (Hct); type 2 diabetes mellitus; meta-analysis

Submitted Mar 22, 2021. Accepted for publication Jun 01, 2021.

doi: 10.21037/apm-21-1022

View this article at: http://dx.doi.org/10.21037/apm-21-1022 


\section{Introduction}

Type 2 diabetes mellitus is a progressive disease characterized by high glucose levels. It is associated with an increased risk of cardiovascular death, myocardial infarction, stroke, and heart failure (HF) $(1,2)$.

Sodium glucose co-transporter (SGLT) 2 inhibitors reduce blood glucose levels by inhibiting the reabsorption of glucose through the SGLT2 receptors in the proximal tubule of the kidneys $(3,4)$. Large-scale randomized controlled trials (RCTs) including EMPA-REG OUTCOME, CANVAS, DECLARE-TIMI58, DAPA-HF, and CREDENCE, have shown that SGLT2 inhibitors can exert cardiorenal benefits (5).

Hematocrit (Hct) is the volume percentage of red cells in total blood and it may be related to mortality and coronary heart disease $(6,7)$. Previous studies have indicated a dual effect of Hct on all-cause mortality and morbidity from cardiovascular diseases (CVDs), and the effects tend to be J- or U- shaped. Furthermore, Hct was significantly related to the incidence of CVD, myocardial infarction, stroke, and coronary heart disease in younger patients, suggesting that Hct is an important risk factor associated with some CVD events (8). Lowe et al. (9) reported that a $3.8 \%$ elevation in Hct was associated with a $39 \%$ increased risk for stroke, suggesting that high Hct levels are related to an increased risk of cardiovascular outcomes. While the upper limit of Hct level varys, the conclusion is consistently that high hematocrit increases the risk of some cardiovascular disease. In addition, Hct has also been shown to play an important role in blood viscosity and oxygen delivery dynamics. An increased Hct level within normal ranges may be beneficial to the vasculature $(8,10-13)$. This meta-analysis of RCTs was conducted to determine the effects of SGLT2 inhibitors on Hct levels in patients with type 2 diabetes mellitus. We present the following article in accordance with the PRISMA reporting checklist (available at http://dx.doi. org/10.21037/apm-21-1022).

\section{Methods}

\section{Search strategy}

This meta-analysis was performed according to the Preferred Reporting Items for Systematic Review and Meta-Analysis (PRISMA) Statement and was registered with the International Prospective Register of Systematic Reviews (CRD42020200699)(14). The following electronic databases were searched from inception to July 2020: Embase, Cochrane Central Register of Controlled Trials (CENTRAL), PubMed, ScienceDirect, Wiley, SpringerLink, and ClinicalTrials.gov. The search terms were as follows: dapagliflozin, canagliflozin, empagliflozin, sotagliflozin, ertugliflozin, ipragliflozin, luseogliflozin, tofogliflozin, SGLT2 inhibitors, and Hct.

\section{Selection criteria}

The literature was selected according to the following inclusion criteria: (I) RCTs involving patients with type 2 diabetes mellitus; (II) the study intervention was SGLT2 inhibitor alone or in combination with other antidiabetic drugs (OAD); (III) the study compared SGLT2 inhibitors with OAD or placebo; and (IV) the study measured changes in Hct levels from baseline. Observational studies, cohort studies, trials with less than 4 weeks duration, and trials and with no comparison data were excluded.

\section{Data extraction}

Two investigators independently reviewed the titles, abstracts, and full text articles. The following information was collated: first author, year of publication, drug of dosage, intervention drug, comparison (OAD or placebo), total number, baseline Hct, baseline age, baseline hemoglobin $(\mathrm{Hb}) \mathrm{A} 1 \mathrm{c}$, baseline body mass index (BMI), duration of therapy, and add-on OAD regimens. Any discrepancies between the two investigators were resolved through discussion and consultation with a third investigator.

\section{Quality assessment}

Risk of bias were independently assessed by two investigators according to the Cochrane collaboration tools, and any disagreements were solved by discussion (15). This tool captures six main sources of bias, including random sequence generation, allocation concealment, blinding of participants and personnel, blinding of outcome assessment, incomplete outcome data, and selective reporting. Each item was defined as low risk, high risk, or unclear risk.

\section{Statistical analysis}

For continuous variables (such as Hct), pooled weighted 


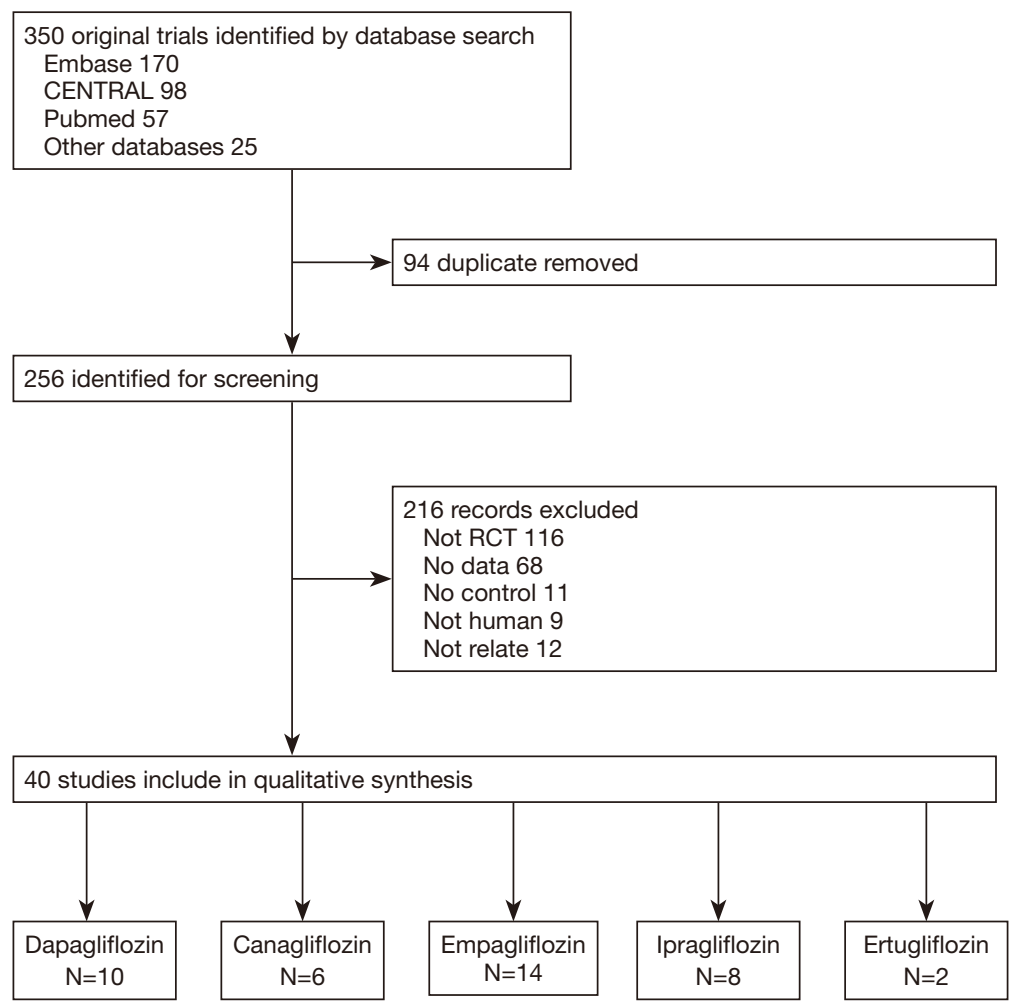

Figure 1 A flowchart summarizing the selection process to identify randomized controlled trials (RCTs) to be included in this meta-analysis.

mean difference (WMD) and 95\% confidence interval (CI) between treatment groups were calculated. Heterogeneity between studies was assessed using $\mathrm{I}^{2}$ statistics. The fixed-effects model was used for analysis if there was no statistical heterogeneity $\left(\mathrm{I}^{2}<50 \%\right)$, otherwise, the random-effects model was used for analysis. Prespecified subgroup analysis was stratified by type and dosage of SGLT2 inhibitor. The WMD and $95 \%$ CI was used to assess the changes in Hct levels from baseline in patients treated with each SGLT2 inhibitor and compared with patients treated with a placebo.

Leave-one-out studies were performed for sensitivity analysis. Meta-regression analyses were performed to evaluate whether the pre-specified covariates of dosage, duration of therapy, add-on therapy, baseline HbA1c, baseline age, and baseline BMI were associated with Hct changes from baseline, corrected for placebo, for each SGLT2 inhibitor. Publication bias was evaluated using Begg's test and Egger's regression analysis. All statistical analyses were conducted with Stata software package (version 12.0; Stata Corp LP, College Station, Texas). The significance level was set at $\alpha=0.05$.

\section{Results}

\section{Summary of the included literature}

Figure 1 summarizes the flowchart of the study selection process. A total of 350 articles were identified and 40 RCTs published from 2009 to 2020 were considered appropriate based on the inclusion criteria. Of these, 10 studies compared dapagliflozin with a placebo as monotherapy or add-on OAD, 6 studies compared canagliflozin with a placebo, 14 studies compared empagliflozin with a placebo, 8 studies compared ipragliflozin with a placebo, and 2 studies compared ertugliflozin with a placebo.

The characteristics of the selected trials are shown in Table 1. The sample size ranged from 36 to 7,020 , totaling 21,050 patients with type 2 diabetes mellitus. The duration of therapy ranged from 4 to 206 weeks. The selected trials enrolled subjects with type 2 diabetes mellitus, hypertension (HP), HF, and chronic kidney disease (CKD).

\section{Risk of bias}

Details for the risk of bias assessment are displayed in Table 2. 


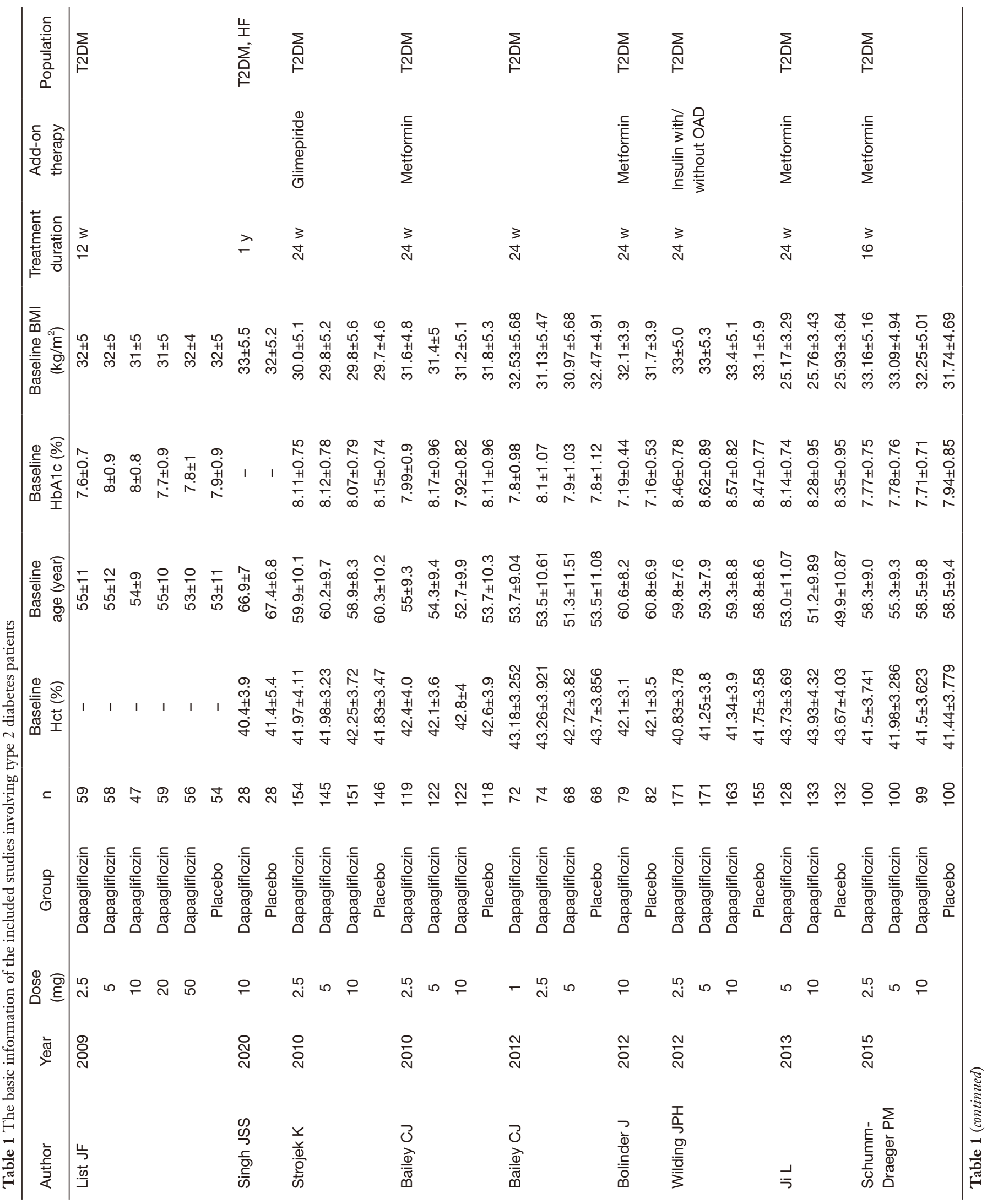




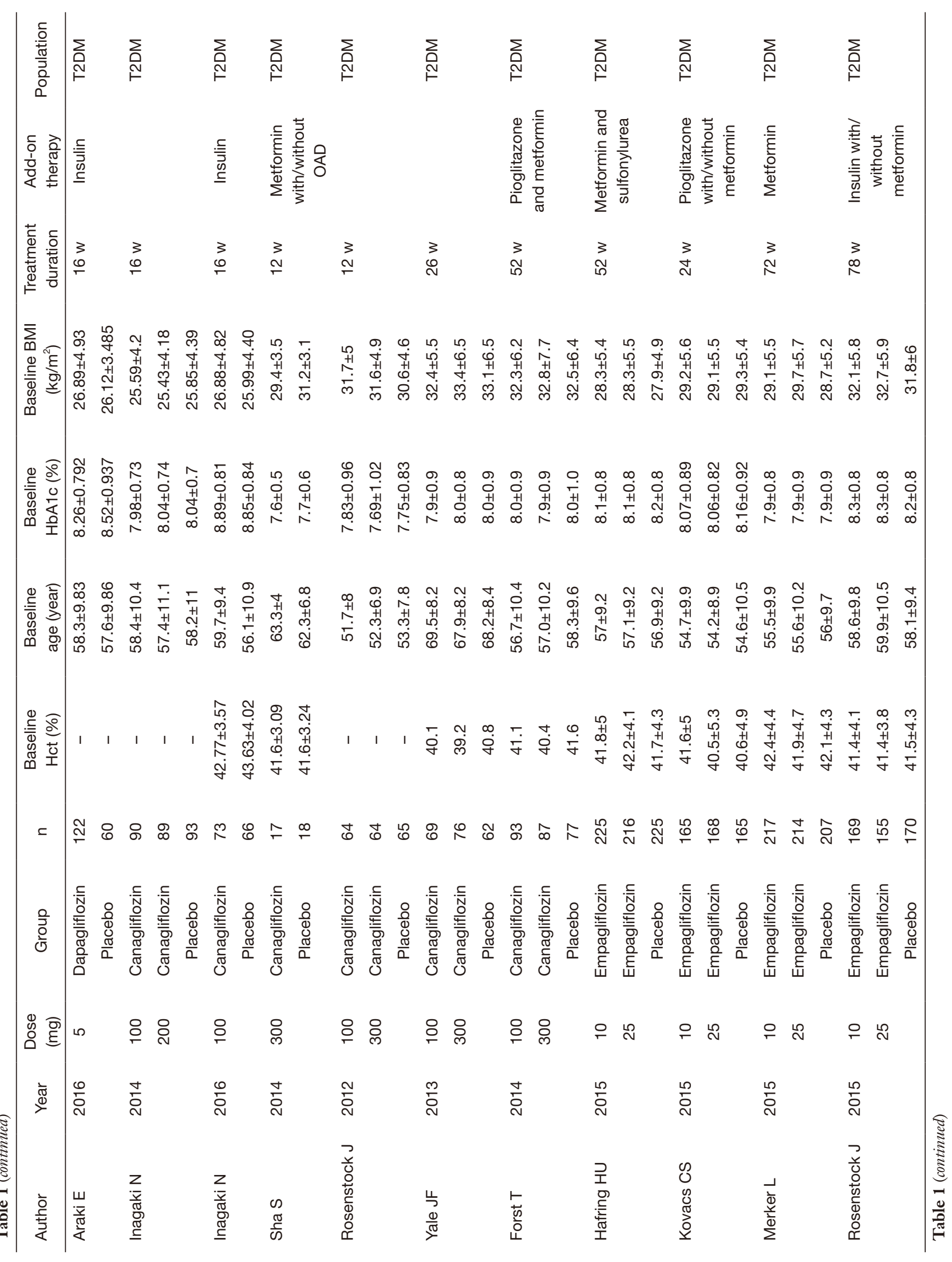




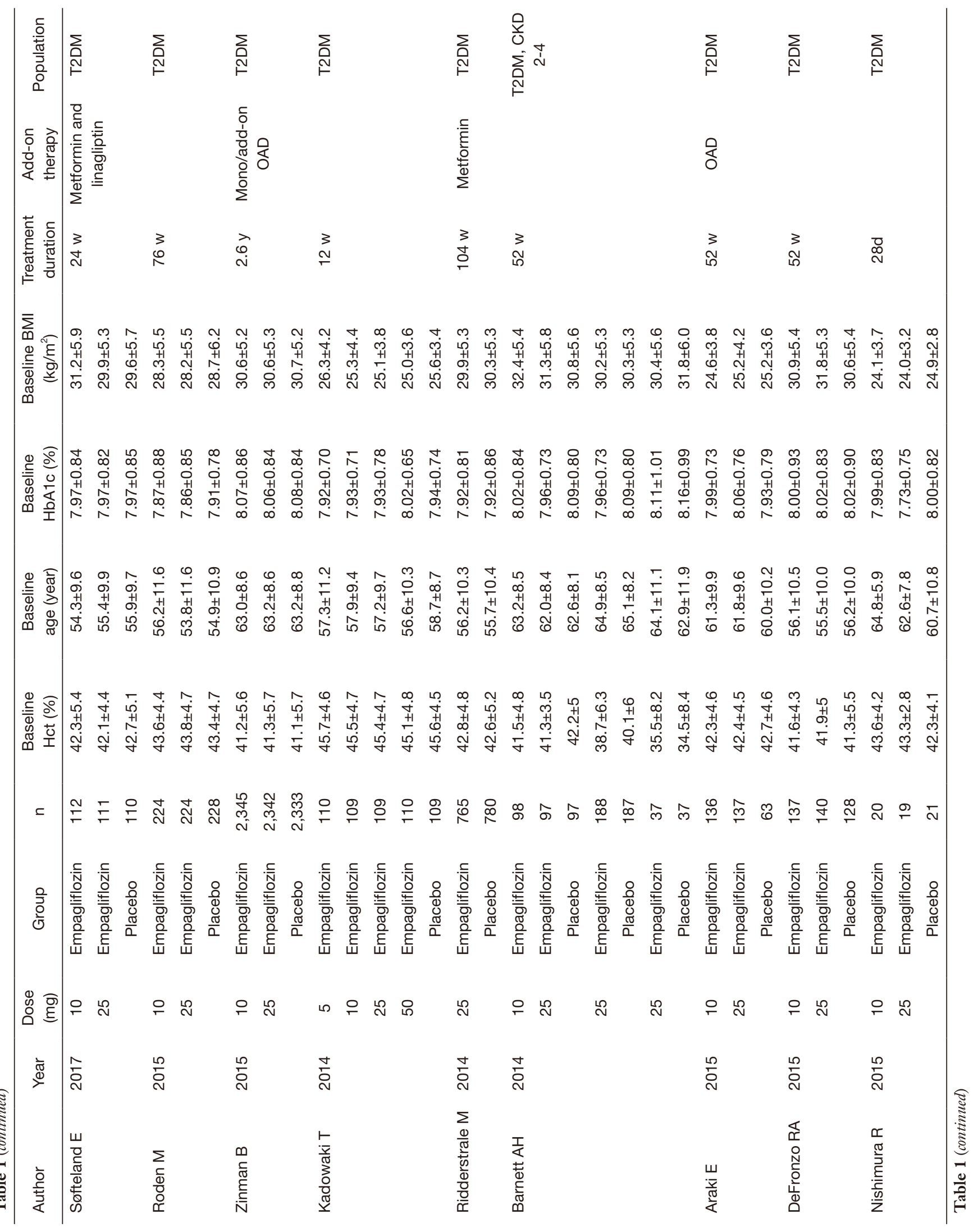




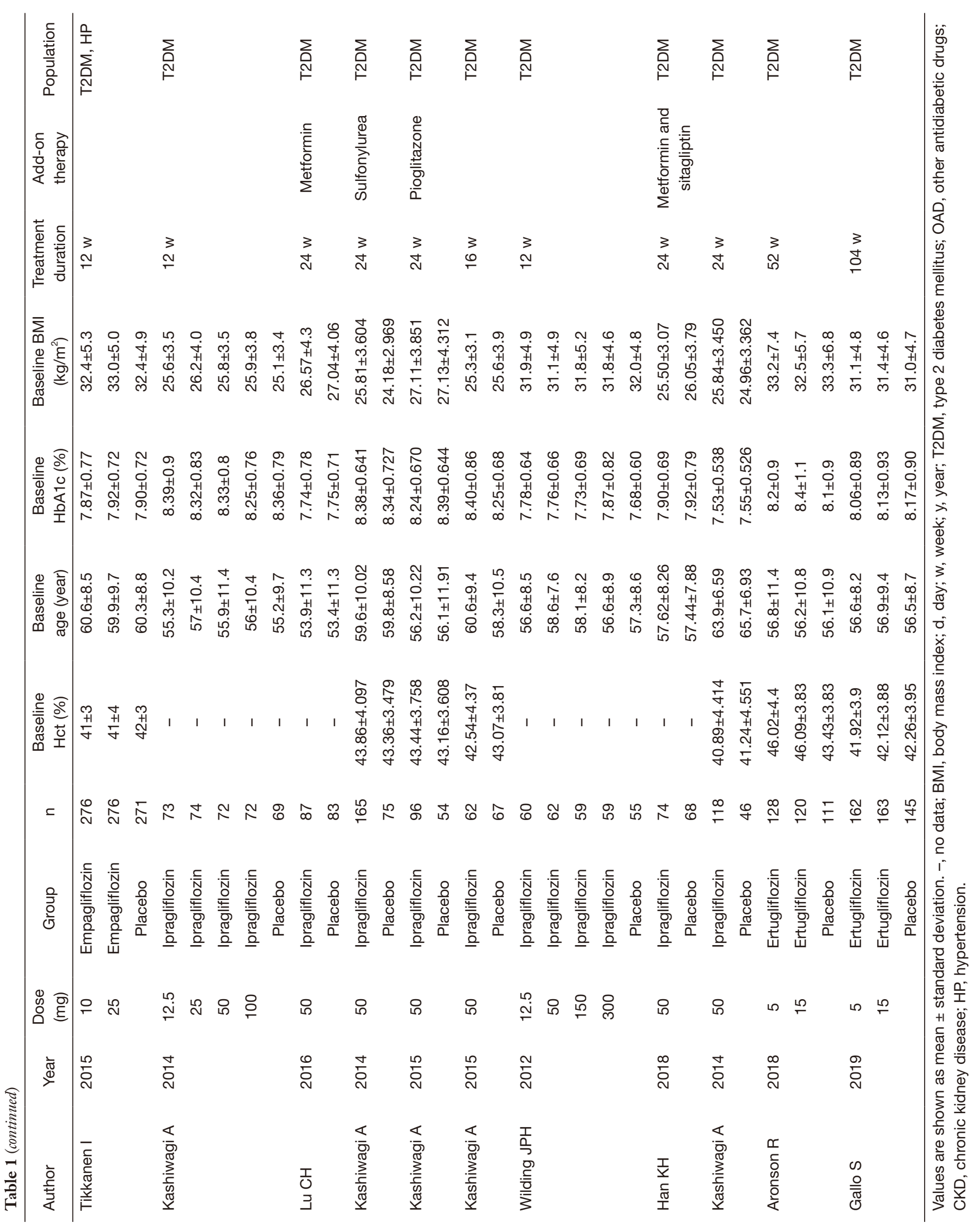


Table 2 Risk of bias assessment of the included studies according to the Cochrane guideline

\begin{tabular}{|c|c|c|c|c|c|c|c|}
\hline Study & $\begin{array}{l}\text { Sequence } \\
\text { generation }\end{array}$ & $\begin{array}{c}\text { Allocation } \\
\text { concealment }\end{array}$ & $\begin{array}{c}\text { Blinding of } \\
\text { participants, } \\
\text { personnel }\end{array}$ & $\begin{array}{l}\text { Outcome } \\
\text { assessors }\end{array}$ & $\begin{array}{l}\text { Incomplete } \\
\text { outcome data }\end{array}$ & $\begin{array}{l}\text { Selective } \\
\text { outcome } \\
\text { reporting }\end{array}$ & Other bias \\
\hline List JF 2009 & $U$ & $U$ & $\mathrm{~L}$ & $U$ & $\mathrm{~L}$ & L & $\mathrm{L}$ \\
\hline Singh JSS 2020 & $U$ & $U$ & $U$ & $U$ & L & L & $U$ \\
\hline Strojek K 2010 & $\mathrm{~L}$ & $\mathrm{~L}$ & $\mathrm{~L}$ & $\mathrm{~L}$ & L & L & $\mathrm{L}$ \\
\hline Wilding JPH 2012 & $\mathrm{~L}$ & $\mathrm{~L}$ & $\mathrm{~L}$ & $\mathrm{~L}$ & L & L & $\mathrm{L}$ \\
\hline Ji L 2014 & L & $\mathrm{L}$ & $\mathrm{L}$ & U & L & L & $\mathrm{L}$ \\
\hline Schumm-Draeger PM 2015 & $\mathrm{~L}$ & $\mathrm{~L}$ & $\mathrm{~L}$ & $\mathrm{~L}$ & $\mathrm{~L}$ & L & $\mathrm{L}$ \\
\hline Araki E 2016 & U & $U$ & $\mathrm{~L}$ & U & L & L & U \\
\hline Sha S 2014 & $\mathrm{H}$ & U & $\mathrm{L}$ & $\mathrm{U}$ & L & L & U \\
\hline Rosenstock J 2012 & U & $U$ & $\mathrm{~L}$ & $\mathrm{~L}$ & L & L & $U$ \\
\hline Yale JF 2013 & $\mathrm{~L}$ & $\mathrm{~L}$ & $\mathrm{~L}$ & $\mathrm{~L}$ & $\mathrm{~L}$ & L & L \\
\hline Forst T 2014 & $\mathrm{~L}$ & $\mathrm{~L}$ & $\mathrm{~L}$ & L & L & L & $\mathrm{L}$ \\
\hline Haering HU 2015 & U & U & $\mathrm{L}$ & $\mathrm{L}$ & $\mathrm{L}$ & L & $U$ \\
\hline Kovacs CS 2015 & $\mathrm{~L}$ & $\mathrm{~L}$ & $\mathrm{~L}$ & U & L & L & $\mathrm{L}$ \\
\hline Merker L 2015 & U & $U$ & $\mathrm{~L}$ & U & $\mathrm{L}$ & L & $U$ \\
\hline Rosenstock J 2015 & $\mathrm{~L}$ & $\mathrm{~L}$ & $\mathrm{~L}$ & U & $\mathrm{H}$ & L & $\mathrm{L}$ \\
\hline Araki E 2015 & $\mathrm{~L}$ & $\mathrm{~L}$ & $\mathrm{~L}$ & U & $\mathrm{L}$ & L & L \\
\hline Defronzo RA 2015 & $\mathrm{~L}$ & $\mathrm{~L}$ & $\mathrm{~L}$ & $U$ & $\mathrm{~L}$ & L & $\mathrm{L}$ \\
\hline Nishimura R 2015 & U & U & $\mathrm{L}$ & $\mathrm{U}$ & $\mathrm{H}$ & L & U \\
\hline Tikkanen I 2015 & $\mathrm{~L}$ & $\mathrm{~L}$ & $\mathrm{~L}$ & U & $\mathrm{H}$ & L & $\mathrm{L}$ \\
\hline Kashiwagi A 2014 & U & $U$ & $\mathrm{~L}$ & $\mathrm{~L}$ & U & L & U \\
\hline Lu CH 2016 & $\mathrm{~L}$ & $\mathrm{~L}$ & $\mathrm{~L}$ & $\mathrm{~L}$ & $\mathrm{~L}$ & $\mathrm{~L}$ & $\mathrm{~L}$ \\
\hline Kashiwagi A 2014 & $\mathrm{~L}$ & $\mathrm{~L}$ & $\mathrm{~L}$ & $\mathrm{~L}$ & $\mathrm{~L}$ & L & L \\
\hline Kashiwagi A 2015 & $\mathrm{~L}$ & $\mathrm{~L}$ & $\mathrm{~L}$ & $\mathrm{~L}$ & $\mathrm{~L}$ & L & L \\
\hline Kashiwagi A 2015 & $\mathrm{H}$ & $U$ & $\mathrm{~L}$ & U & $\mathrm{L}$ & L & U \\
\hline Wilding JPH 2012 & $\mathrm{H}$ & U & $\mathrm{L}$ & L & $\mathrm{L}$ & L & L \\
\hline Han KH 2018 & $\mathrm{~L}$ & $\mathrm{~L}$ & $\mathrm{~L}$ & $\mathrm{~L}$ & $\mathrm{~L}$ & L & $\mathrm{L}$ \\
\hline Kashiwagi A 2014 & $\mathrm{H}$ & $\mathrm{L}$ & $\mathrm{L}$ & L & U & L & U \\
\hline Aronson R 2018 & $\mathrm{~L}$ & $\mathrm{~L}$ & $\mathrm{~L}$ & L & U & L & $\mathrm{L}$ \\
\hline Gallo S 2019 & $\mathrm{~L}$ & L & $\mathrm{L}$ & $\mathrm{L}$ & $\mathrm{L}$ & L & $\mathrm{L}$ \\
\hline
\end{tabular}

$\mathrm{L}$, low risks of bias; $\mathrm{H}$, high risks of bias; $U$, unclear risks of bias. 
The majority of included studies had a low risk of bias for random sequence generation, allocation concealment, and blinding of participants and personnel. However, 17 included studies showed insufficient information regarding blinding of outcome assessment. Additionally, 3 clinical trials showed a high risk of bias for incomplete outcome data, and 3 clinical trials had an uncleared risk of bias. Finally, all studies showed a low risk of bias for selective outcome reporting. There was no evidence of publication bias, as demonstrated by Begg's test $(\mathrm{P}=0.898)$ and Egger's regression analysis $(\mathrm{P}=0.162)$.

\section{The effect of SGLT2 inbibitors on Hct levels}

This meta-analysis demonstrated that overall, the SGLT2 inhibitors caused a significant increase in Hct levels (WMD 2.67\%, 95\% CI, 2.53 to $2.82, \mathrm{I}^{2}=98.5 \%, \mathrm{P}<0.001$ ). Furthermore, each of the following SGLT2 inhibitors significantly increased Hct levels, including dapagliflozin (WMD 2.25\%, 95\% CI, 2.02 to $2.48, \mathrm{I}^{2}=99.5 \%, \mathrm{P}<0.001$ ), canagliflozin (WMD 2.63\%, 95\% CI, 2.30 to 2.96, $\mathrm{I}^{2}=83.7 \%, \mathrm{P}<0.001$ ), and empagliflozin (WMD 3.42\%, $95 \%$ CI, 3.09 to $\left.3.75, \mathrm{I}^{2}=86.8 \%, \mathrm{P}<0.001\right)$. Ipragliflozin (WMD $1.85 \%, 95 \%$ CI, 1.62 to $2.07, \mathrm{I}^{2}=0 \%, \mathrm{P}>0.05$ ), and ertugliflozin (WMD 2.45\%, 95\% CI, 2.14 to $2.76, \mathrm{I}^{2}=0 \%$, $\mathrm{P}>0.05$ ) only slightly increased Hct levels. Details are presented in Figure 2.

The Hct level increased slightly more in high-dose patients compared to low-dose patients. Compared with placebo, dapagliflozin at $2.5,5$, and $10 \mathrm{mg}$ led to a significant increase in Hct levels (WMD 1.96\%, 2.27\%, and $2.47 \%$, respectively; $\mathrm{P}<0.001$; Figure 3). Treatment with canagliflozin 100 and $300 \mathrm{mg}$ also resulted in a notable increase in Hct levels (WMD 2.91\% and 2.94\%, respectively; $\mathrm{P}<0.001 ;$ Figure 4$)$. Patients treated with empagliflozin at 10 and $25 \mathrm{mg}$ also demonstrated an apparent increase in Hct levels (WMD 3.39\% and 3.44\%, respectively; $\mathrm{P}<0.001$; Figure 5). However, treatment with ipragliflozin at 12.5 and $50 \mathrm{mg}$ (WMD $1.26 \%$ and $1.98 \%$, respectively; $\mathrm{P}>0.05$; Figure 6) and treatment with ertugliflozin at 5 and $15 \mathrm{mg}$ (WMD 2.24\% and 2.64\%, respectively; $\mathrm{P}>0.05$; Figure 7 ) only resulted in a slight increase in Hct levels.

\section{Sensitivity analysis and meta-regressions}

The sensitivity analysis demonstrated that all included trials showed a similar consistent trend with the pooled analysis, and none of the studies were omitted. Several metaregression analyses were performed to evaluate whether the pre-specified covariates of dosage, duration of therapy, addon therapy, baseline $\mathrm{HbA1c}$, baseline age, and baseline BMI were associated with Hct changes from baseline, corrected for placebo, for each SGLT2 inhibitor. In patients who received canagliflozin treatment, the increase in Hct levels was associated with the duration of therapy. In patients who received empagliflozin treatment, elevated Hct levels were associated with add-on therapy. No other associations were detected between each SGLT2 inhibitor and the aforementioned factors. $\beta$ coefficients and $\mathrm{P}$ values are shown in Table 3.

\section{Discussion}

The present meta-analysis of 40 RCTs quantified the ability of SGLT2 inhibitors to increase Hct levels in patients with type 2 diabetes mellitus. Dapagliflozin, canagliflozin, and empagliflozin significantly increased the levels of Hct, while ipragliflozin and ertugliflozin led to a slight increase, suggesting that SGLT2 inhibitors displayed a class effect. The increase in Hct levels was slightly more pronounced at high doses compared to low doses.

Previous studies have shown the ability of SGLT2 inhibitors to increase Hct levels from baseline (16). This meta-analysis demonstrated that SGLT2 inhibitors may have a class effect on Hct levels, with empagliflozin exerting the largest increase in Hct levels, followed by canagliflozin, ertugliflozin, dapagliflozin, and ipragliflozin.

There are several possible mechanisms by which SGLT2 inhibitors increase Hct levels. Sano et al. attributed the Hct increase to diuretic effects (17). This latter study demonstrated that SGLT2 inhibitors increased urine volume, reaching a peak at 24 hours and recovering to baseline about 1 week later, while the Hct continued to increase beyond 2 months (17). Lambers Heerspink et al. (18) suggested that the increase in Hct was related to erythropoiesis. Treatment with dapagliflozin increased erythropoietin levels, reaching a peak range at 2 to 4 weeks after treatment. Meanwhile, the number of reticulocytes was elevated, followed by an increase in hemoglobin and Hct levels. Under normal conditions, fibroblasts near the proximal tubule in the kidneys produce erythropoietin. When proximal tubular epithelial cells are selectively injured, this induces the transdifferentiation of fibroblasts into myofibroblasts, thereby reducing the production of erythropoietin $(13,17)$. SGLT2 inhibitors improve ATP 


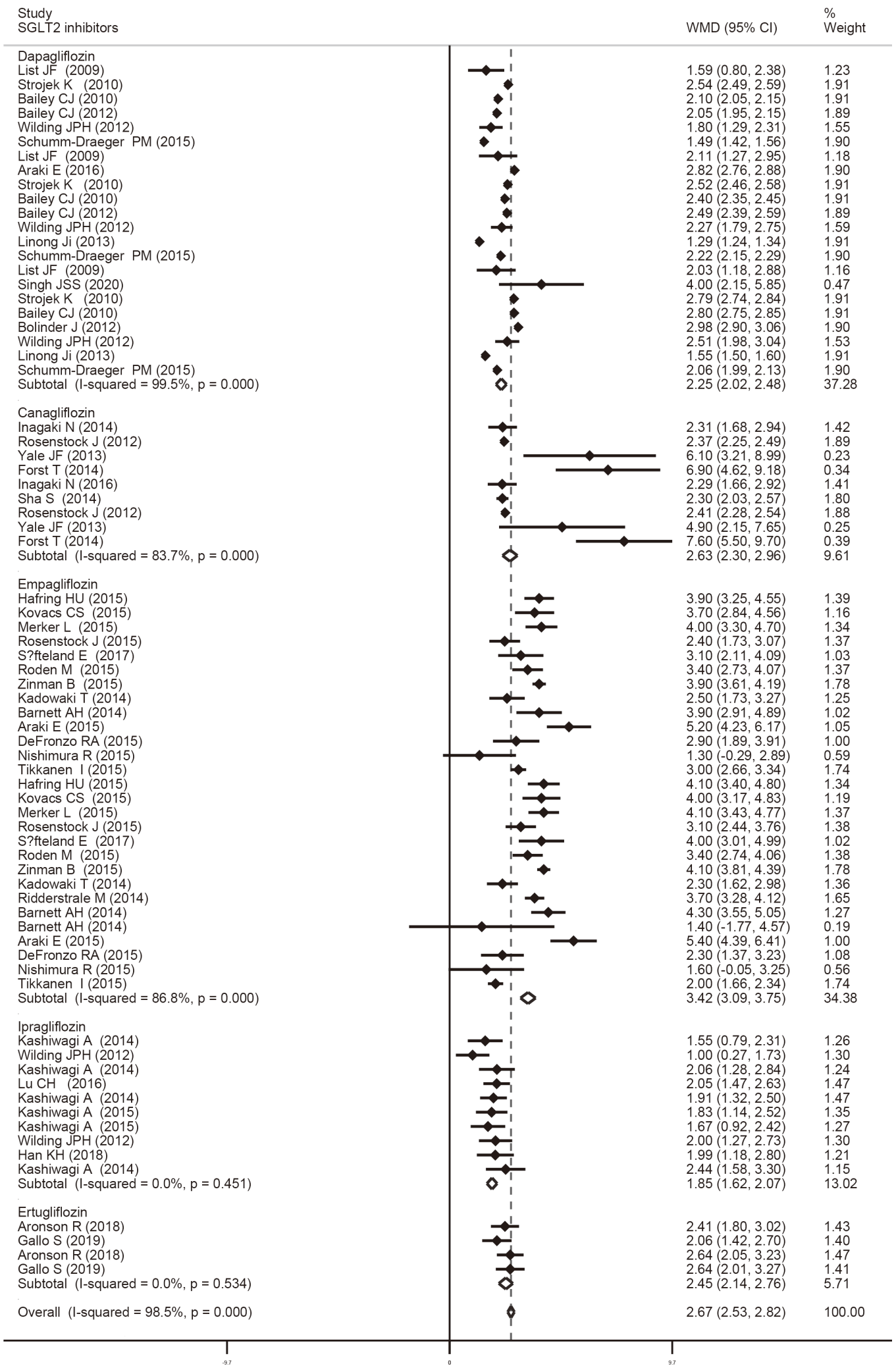

Figure 2 The weighted mean difference (WMD) and 95\% confidence intervals (CI) for the effects of SGLT2 inhibitors on hematocrit levels, stratified by dosage. SGLT2, sodium glucose co-transporter 2. 


\begin{tabular}{|c|c|c|c|}
\hline \multicolumn{2}{|l|}{$\begin{array}{l}\text { Study } \\
\text { Dapagliflozin }\end{array}$} & \multirow[t]{2}{*}{ WMD (95\% Cl) } & $\begin{array}{l}\% \\
\text { Weight }\end{array}$ \\
\hline $2.5 \mathrm{mg}$ & i & & \\
\hline List JF (2009) & $\rightarrow-1$ & $1.59(0.80,2.38)$ & 3.23 \\
\hline Strojek K (2010) & $\bullet$ & $2.54(2.49,2.59)$ & 5.14 \\
\hline Bailey CJ (2010) & $\bullet$ & $2.10(2.05,2.15)$ & 5.14 \\
\hline Bailey CJ (2012) & $\bullet$ & $2.05(1.95,2.15)$ & 5.10 \\
\hline Wilding JPH (2012) & $\rightarrow 1$ & $1.80(1.29,2.31)$ & 4.12 \\
\hline Schumm-Draeger PM (2015) & - 1 & $1.49(1.42,1.56)$ & 5.13 \\
\hline Subtotal $(I-$ squared $=99.2 \%, p=0.000)$ & $\checkmark$ & $1.96(1.58,2.34)$ & 27.87 \\
\hline $5 \mathrm{mg}$ & i & & \\
\hline List JF (2009) & 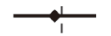 & $2.11(1.27,2.95)$ & 3.09 \\
\hline Araki E (2016) & 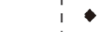 & $2.82(2.76,2.88)$ & 5.13 \\
\hline Strojek K (2010) & $\bullet$ & $2.52(2.46,2.58)$ & 5.14 \\
\hline Bailey CJ (2010) & $\leftrightarrow$ & $2.40(2.35,2.45)$ & 5.14 \\
\hline Bailey CJ (2012) & 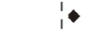 & $2.49(2.39,2.59)$ & 5.11 \\
\hline Wilding JPH (2012) & $\rightarrow$ & $2.27(1.79,2.75)$ & 4.24 \\
\hline Linong Ji (2013) & - $\quad \vdots$ & $1.29(1.24,1.34)$ & 5.14 \\
\hline Schumm-Draeger PM (2015) & 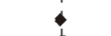 & $2.22(2.15,2.29)$ & 5.13 \\
\hline Subtotal $(\mid-$-squared $=99.6 \%, p=0.000)$ & & $2.27(1.87,2.68)$ & 38.12 \\
\hline $10 \mathrm{mg}$ & $\begin{array}{l}1 \\
1\end{array}$ & & \\
\hline List JF (2009) & $\frac{1}{1}$ & $2.03(1.18,2.88)$ & 3.05 \\
\hline Singh JSS (2020) & 1 & $4.00(2.15,5.85)$ & 1.21 \\
\hline Strojek K (2010) & i & $2.79(2.74,2.84)$ & 5.14 \\
\hline Bailey CJ (2010) & $\bullet$ & $2.80(2.75,2.85)$ & 5.14 \\
\hline Bolinder J (2012) & i & $2.98(2.90,3.06)$ & 5.12 \\
\hline Wilding JPH (2012) & $\stackrel{1}{1}$ & $2.51(1.98,3.04)$ & 4.07 \\
\hline Linong Ji (2013) & $\begin{array}{c}1 \\
-1\end{array}$ & $1.55(1.50,1.60)$ & 5.14 \\
\hline Schumm-Draeger PM (2015) & $\bullet$ & $2.06(1.99,2.13)$ & 5.13 \\
\hline Subtotal $(\mid$-squared $=99.6 \%, p=0.000)$ & $<$ & $2.47(2.01,2.93)$ & 34.01 \\
\hline Overall $(I-$ squared $=99.5 \%, p=0.000)$ & (1) & $2.25(2.02,2.48)$ & 100.00 \\
\hline & 1 & & \\
\hline $\begin{array}{c}1 \\
-5.85\end{array}$ & & & \\
\hline
\end{tabular}

Figure 3 The weighted mean difference (WMD) and 95\% confidence intervals (CI) for the effects of dapagliflozin treatment on Hct levels, stratified by dosage.

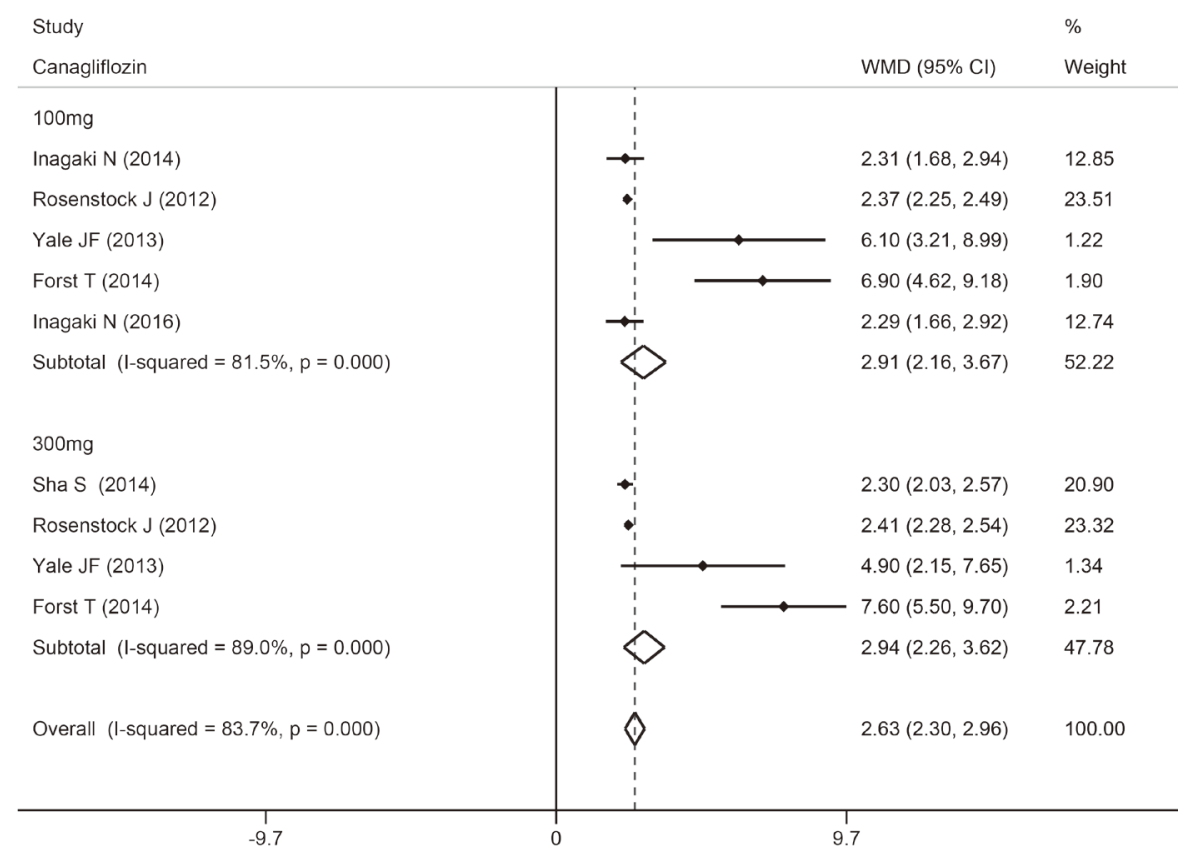

Figure 4 The weighted mean difference (WMD) and 95\% confidence intervals (CI) for the effects of canagliflozin treatment on Hct levels, stratified by dosage. 


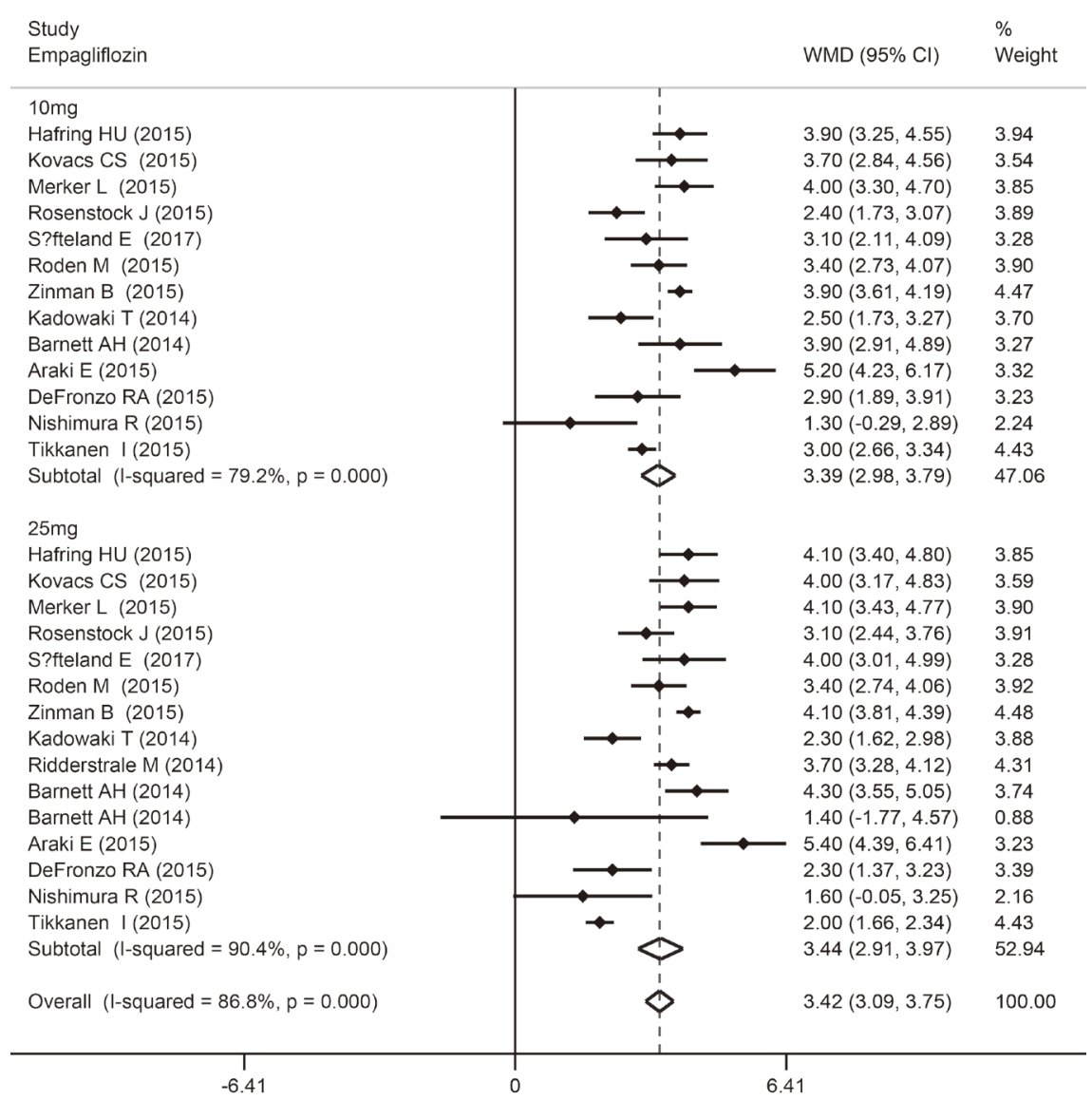

Figure 5 The weighted mean difference (WMD) and 95\% confidence intervals (CI) for the effects of empagliflozin treatment on Hct levels, stratified by dosage.

consumption via the sodium/potassium $\left(\mathrm{Na}^{+} / \mathrm{K}^{+}\right)$pump and mitigate metabolic stress to the proximal tubular epithelial cells, which may reverse the transdifferentiating fibroblasts into erythropoietin-producing fibroblasts, thereby increasing Hct levels (19-21).

Several limitations of this meta-analysis should be considered. First, the inclusion criteria and the baseline characteristics, such as ethnicity, age, BMI, HbA1c, baseline Hct, duration of therapy, and add-on therapy, may vary across studies resulting in a high level of heterogeneity. While the random-effects model, sensitivity analyses, and several meta-regression analyses were performed, these results should be interpreted with caution. The interstudy heterogeneity of ipragliflozin and ertugliflozin were low, and thus the related meta-regressions could not be conducted. Second, the complete data set was not available for all studies. For example, in the study by Yale and colleagues (5), 100 and $300 \mathrm{mg}$ canagliflozin were compared with the same placebo group. Finally, ertugliflozin was only included in two studies. Therefore, future clinical trials are warranted to comprehensively determine the effects of ertugliflozin treatment on Hct levels.

In conclusion, SGLT2 inhibitors demonstrated a class effect by increasing Hct levels. Empagliflozin had the most significantly effect on Hct levels, followed by canagliflozin, ertugliflozin, dapagliflozin, and ipragliflozin. Hence, it can be suggested that patients with high baseline Hct or excessive Hct elevation should be carefully treated with SGLT2 inhibitors. However, further clinical trials are necessary to clarify these results. 


\begin{tabular}{|c|c|c|}
\hline \multicolumn{2}{|l|}{ Study } & $\%$ \\
\hline Ipragliflozin & WMD $(95 \% \mathrm{Cl})$ & Weight \\
\hline \multicolumn{3}{|l|}{$12.5 \mathrm{mg}$} \\
\hline Kashiwagi A (2014) & $1.55(0.79,2.31)$ & 8.73 \\
\hline Wilding JPH (2012) & $1.00(0.27,1.73)$ & 9.45 \\
\hline Subtotal $(I-$ squared $=4.1 \%, p=0.307$ ) & $1.26(0.73,1.80)$ & 18.18 \\
\hline \multicolumn{3}{|l|}{$50 \mathrm{mg}$} \\
\hline Kashiwagi A (2014) & $2.06(1.28,2.84)$ & 8.26 \\
\hline $\mathrm{LuCH}$ (2016) & $2.05(1.47,2.63)$ & 15.03 \\
\hline Kashiwagi A (2014) & $1.91(1.32,2.50)$ & 14.75 \\
\hline Kashiwagi A (2015) & $1.83(1.14,2.52)$ & 10.71 \\
\hline Kashiwagi A (2015) & $1.67(0.92,2.42)$ & 8.89 \\
\hline Wilding JPH (2012) & $2.00(1.27,2.73)$ & 9.59 \\
\hline Han KH (2018) & $1.99(1.18,2.80)$ & 7.75 \\
\hline Kashiwagi A (2014) & $2.44(1.58,3.30)$ & 6.82 \\
\hline Subtotal $(I-$ squared $=0.0 \%, p=0.955)$ & $1.98(1.73,2.23)$ & 81.82 \\
\hline Overall $(I-$ squared $=0.0 \%, p=0.451)$ & $1.85(1.62,2.07)$ & 100.00 \\
\hline $\begin{array}{ll}1 \\
-3.3\end{array}$ & 3 & \\
\hline
\end{tabular}

Figure 6 The weighted mean difference (WMD) and 95\% confidence intervals (CI) for the effects of ipragliflozin treatment on Hct levels, stratified by dosage.

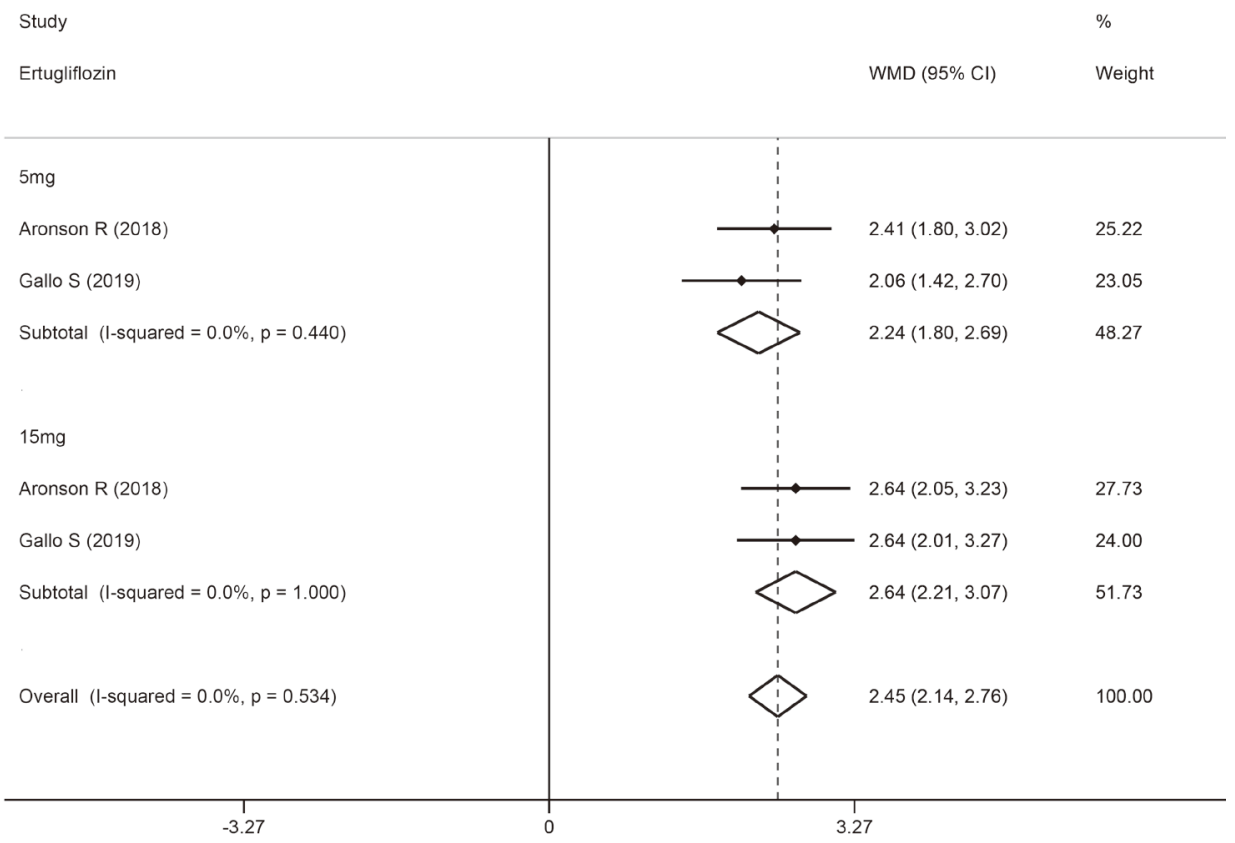

Figure 7 The weighted mean difference (WMD) and 95\% confidence intervals (CI) for the effects of ertugliflozin treatment on Hct levels, stratified by dosage. 
Table 3 Meta-regression analysis of the association between changes in hematocrit (Hct), corrected for placebo, and dosage, duration of therapy, add-on therapy, baseline HbA1c, baseline age, and baseline body mass index (BMI) for a specific sodium glucose co-transporter (SGLT) 2 inhibitor ( $\beta$ coefficient values and $\mathrm{P}$ values are displayed)

\begin{tabular}{lccc}
\hline Variables & Dapagliflozin & Canagliflozin & Empagliflozin \\
\hline Dosage & $0.07(0.068)$ & $0.002(0.827)$ & $0.005(0.839)$ \\
Duration of therapy & $0.88(0.116)$ & $2.53(0.001)$ & $0.28(0.053)$ \\
Add-on therapy & $-0.15(0.57)$ & $1.14(0.476)$ & $0.89(0.009)$ \\
Baseline HbA1c & $-0.12(0.642)$ & $0.90(0.603)$ & $0.34(0.359)$ \\
Baseline age & $0.69(0.057)$ & $0.41(0.817)$ & $0.47(0.229)$ \\
Baseline BMI & $0.09(0.738)$ & $2.4(0.113)$ & $-0.38(0.294)$ \\
\hline
\end{tabular}

\section{Acknowledgments}

Funding: None.

\section{Footnote}

Reporting Checklist: The authors have completed the PRISMA reporting checklist. Available at http://dx.doi. org/10.21037/apm-21-1022

Conflicts of Interest: All authors have completed the ICMJE uniform disclosure form (available at http://dx.doi. org/10.21037/apm-21-1022). The authors have no conflicts of interest to declare.

Ethical Statement: The authors are accountable for all aspects of the work in ensuring that questions related to the accuracy or integrity of any part of the work are appropriately investigated and resolved.

Open Access Statement: This is an Open Access article distributed in accordance with the Creative Commons Attribution-NonCommercial-NoDerivs 4.0 International License (CC BY-NC-ND 4.0), which permits the noncommercial replication and distribution of the article with the strict proviso that no changes or edits are made and the original work is properly cited (including links to both the formal publication through the relevant DOI and the license). See: https://creativecommons.org/licenses/by-nc-nd/4.0/.

\section{References}

1. Ferrannini E, DeFronzo RA. Impact of glucose-lowering drugs on cardiovascular disease in type 2 diabetes. Eur Heart J 2015;36:2288-96.
2. Shah AD, Langenberg C, Rapsomaniki E, et al. Type 2 diabetes and incidence of cardiovascular diseases: a cohort study in 1.9 million people. Lancet Diabetes Endocrinol 2015;3:105-13.

3. Zelniker TA, Braunwald E. Clinical Benefit of Cardiorenal Effects of Sodium-Glucose Cotransporter 2 Inhibitors: JACC State-of-the-Art Review. J Am Coll Cardiol 2020;75:435-47.

4. Gerich JE. Role of the kidney in normal glucose homeostasis and in the hyperglycaemia of diabetes mellitus: therapeutic implications. Diabet Med 2010;27:136-42.

5. Yale JF, Bakris G, Cariou B, et al. Efficacy and safety of canagliflozin in subjects with type 2 diabetes and chronic kidney disease. Diabetes Obes Metab 2013;15:463-73.

6. Sorlie PD, Garcia-Palmieri MR, Costas R, et al. Hematocrit and risk of coronary heart disease: the Puerto Rico Heart Health Program. Am Heart J 1981;101:45661.

7. Kunnas T, Solakivi T, Huuskonen K, et al. Hematocrit and the risk of coronary heart disease mortality in the TAMRISK study, a 28-year follow-up. Prev Med 2009;49:45-7.

8. Gagnon DR, Zhang TJ, Brand FN, et al. Hematocrit and the risk of cardiovascular disease-The Framingham Study: A 34-year follow-up. Am Heart J 1994;127:674-82.

9. Lowe GDO, Lee AJ, Rumley A, et al. Blood viscosity and risk of cardiovascular events: the Edinburgh Artery Study. Br J Haematol 1997;96:168-73.

10. Gotoh S, Hata J, Ninomiya T, et al. Hematocrit and the risk of cardiovascular disease in a Japanese community: The Hisayama Study. Atherosclerosis 2015;242:199-204.

11. Kishimoto S, Maruhashi T, Kajikawa M, et al. Hematocrit, hemoglobin and red blood cells are associated with vascular function and vascular structure in men. Sci Rep 
2020;10:11467.

12. Toss F, Nordström A, Nordström P. Association between hematocrit in late adolescence and subsequent myocardial infarction in Swedish men. Int J Cardiol 2013;168:3588-93.

13. Sano M, Takei M, Shiraishi Y, et al. Increased Hematocrit During Sodium-Glucose Cotransporter 2 Inhibitor Therapy Indicates Recovery of Tubulointerstitial Function in Diabetic Kidneys. J Clin Med Res 2016;8:844-47.

14. Moher D, Shamseer L, Clarke M, et al. Preferred reporting items for systematic review and meta-analysis protocols (PRISMA-P) 2015 statement. Syst Rev 2015;4:1.

15. Higgins JPT, Altman DG, Gøtzsche PC, et al. The Cochrane Collaboration's tool for assessing risk of bias in randomised trials. BMJ 2011;343:d5928.

16. Imprialos KP, Boutari C, Stavropoulos K, et al. Stroke paradox with SGLT-2 inhibitors: A play of chance or a viscosity-mediated reality? J Neurol Neurosurg Psychiatry 2017;88:249-53.

17. Sano M, Goto S. Possible Mechanism of Hematocrit Elevation by Sodium Glucose Cotransporter 2 Inhibitors

Cite this article as: Wang $\mathrm{X}, \mathrm{Fu} \mathrm{R}$, Liu H, Ma Y, Qiu X, Dong Z. The effects of sodium glucose co-transporter (SGLT) 2 inhibitors on hematocrit levels: a systematic review and metaanalysis of randomized controlled trials. Ann Palliat Med 2021;10(6):6467-6481. doi: 10.21037/apm-21-1022 and Associated Beneficial Renal and Cardiovascular Effects. Circulation 2019;139:1985-7.

18. Lambers Heerspink HJ, de Zeeuw D, Wie L, et al. Dapagliflozin a glucose-regulating drug with diuretic properties in subjects with type 2 diabetes. Diabetes Obes Metab 2013;15:853-62.

19. O'Neill J, Fasching A, Pihl L, et al. Acute SGLT inhibition normalizes $\mathrm{O} 2$ tension in the renal cortex but causes hypoxia in the renal medulla in anaesthetized control and diabetic rats. Am J Physiol Renal Physiol 2015;309:F227-34.

20. Takaori K, Nakamura J, Yamamoto S, et al. Severity and Frequency of Proximal Tubule Injury Determines Renal Prognosis. J Am Soc Nephrol 2016;27:2393.

21. Symeonidis A, Kouraklis-Symeonidis A, Psiroyiannis A, et al. Inappropriately low erythropoietin response for the degree of anemia in patients with noninsulin-dependent diabetes mellitus. Ann Hematol 2006;85:79-85.

(English Language Editor: J. Teoh) 